\title{
Regulation of DNA repair machinery in Paracoccidioides brasiliensis during stress induction
}

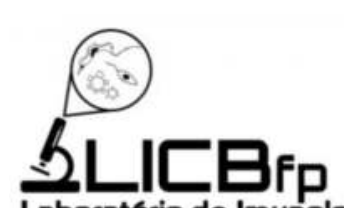

Laboratorio de Imunologia Celular e Bioquímica de Fungos e Protozoários
UNIFESP

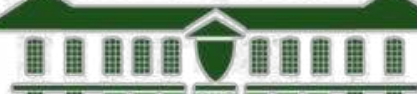

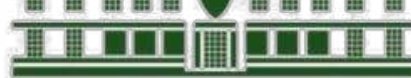

Alison F.A. Chaves ${ }^{1}$, Marina V. Navarro ${ }^{1}$, Daniele G. Castilho ${ }^{1}$, Juliana C. Calado ${ }^{1}$, Palloma M.

Conceição ${ }^{2}$, Beatriz F. de Castro², Wagner L. Batista ${ }^{1,2}$

${ }^{1}$ Department of Microbiology, Immunology and Parasitology, Universidade Federal de São Paulo, São Paulo, Brazi

2 Department of Pharmaceutical Sciences, Universidade Federal de São Paulo, Diadema, São Paulo, Brazil

Correspondence author: felipealison@gmail.com

\section{INTRODUCTION}

$P$. brasiliensis fungus performs the pathogenic switch from mycelium to yeast at $37^{\circ} \mathrm{C}$, the human body temperature and the pathogenic switch involves a series of transcription changes, mainly in virulence related genes and oxidative stress responsive genes. Reactive oxygen species are well known threatening to DNA integrity and the capacity of the fungus to cope with the oxidative stress imposed by the immune cells from the human host is essential to the infection and disease progression Homologous recombination (HR) and non-homologous end joining (NHEJ) are the major players in the DNA repair processes. To assess the regulation of the DNA repair machinery from $P$. brasiliensis under different stress conditions, we performed quantitative PCR from the $P$. brasiliensis genes related to HR (RAD51 and RAD52) and $\mathrm{NHEJ}(K U 70)$ pathways under different $\mathrm{H}_{2} \mathrm{O}_{2}$ concentration $(2.5,5$ or $10 \mathrm{mM})$, heat shock $\left(42^{\circ} \mathrm{C}\right.$ for $30 \mathrm{~min}$ or $\left.60 \mathrm{~min}\right)$, and osmotic stress (50 or $300 \mathrm{mM} \mathrm{NaCl}$ ). Additionally, we used a NHEJ inhibitor (SCR7 pyrazine) to treat the $P$. brasiliensis yeast cells. The cells were submitted to microdilution assay with the inhibitor to determine the non-cytotoxic drug concentration and them we performed the inhibition assay under the conditions above mentioned. $P$. brasiliensis fungus is able to cope with the oxidative stress as reported elsewhere. Here we report that this fungus has a DNA repair machinery responsive to diverse types of stress. When NHEJ inhibitor was added to the medium and cultures treated with increasing $\mathrm{H}_{2} \mathrm{O}_{2}$ concentrations, the fungus shown an unexpected response. After NHEJ inhibition the fungus was able to survive despite the $10 \mathrm{mM} \mathrm{H}_{2} \mathrm{O}_{2}$ concentration. This effect may guard some relation with the activation of HR-related genes to repair the fungus DNA, while NHEJ would be a secondary player at this event. When the fungus was treated with increasing $\mathrm{H}_{2} \mathrm{O}_{2}$ concentrations we observed a dose dependent up-regulation of the $\mathrm{HR}$ and NHEJ related genes. KU70 (NHEJ-related gene) increased its expression when $10 \mathrm{mM} \mathrm{H}_{2} \mathrm{O}_{2}$ was added to cultures. At the same condition, RAD51 and RAD52 (HR-related genes) increased 5 and near to 30 -fold, respectively. When yeast cells were exposed to $42^{\circ} \mathrm{C}$ during 60 min, we observed a more modest 2-fold increase in KU70 expression, suggesting that the DNA repair genes are less sensitive to this type of stress. No differences were observed regarding the cell morphology (mycelium or yeast). Finally, KU70 is up-regulated under osmotic stress $(300 \mathrm{mM} \mathrm{NaCl})$ what led us to conjecture a role to this NHEJ-related gene in the Hog1 pathway. $P$. brasiliensis is a high complex fungus with an intricate repertoire of responses to the stress imposed to immune cells from the host. It repertoire includes, but not limited to, a sophisticated DNA repair machinery able to cope with the oxidative stress. Our findings reveals that KU70, RAD51, and RAD52 genes are up-regulated by the oxidative stress, suggesting that DNA is actually under threatening at these conditions. $P$. brasiliensis expressed all the genes important for the repair via homologous recombination and non-homologous end joining. In P. brasiliensis, the DNA repair machinery is regulated by both Hog1 and Ras pathways and, finally but not less important, genes involved with homologous recombination have the expression induced during oxidative stress.

\section{RESULTS}

A
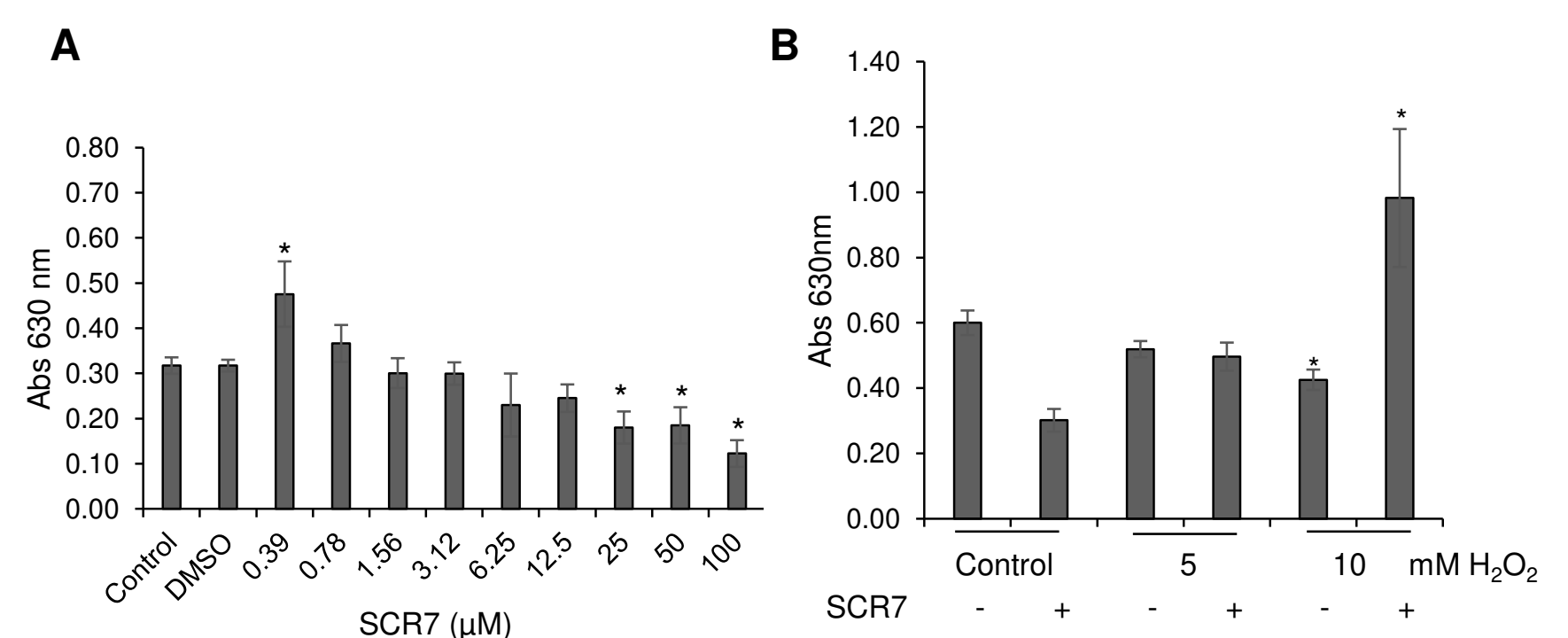

Figure 1. Effect of NHEJ pathway inhibitor on P. brasiliensis growth. (A) $2 \times 10^{5}$ cel.mL-1 were seeded in 96 well plates in quintuplicate, treated with increasing SCR7 pirazine concentrations $(0.39-100 \mu \mathrm{M})$ and incubated during 10 days at $37^{\circ} \mathrm{C}$. Note that important differences in growth profile of the fungus were only observed treated with high $\mathrm{H}_{2} \mathrm{O}_{2}$ concentration. A suspension of $2 \times 105$ cel. $\mathrm{mL}^{-1}$. P. brasliensis yeast cells was seeded stimuli. * $p$-valor $\leq 0.05$ as compared to controls.

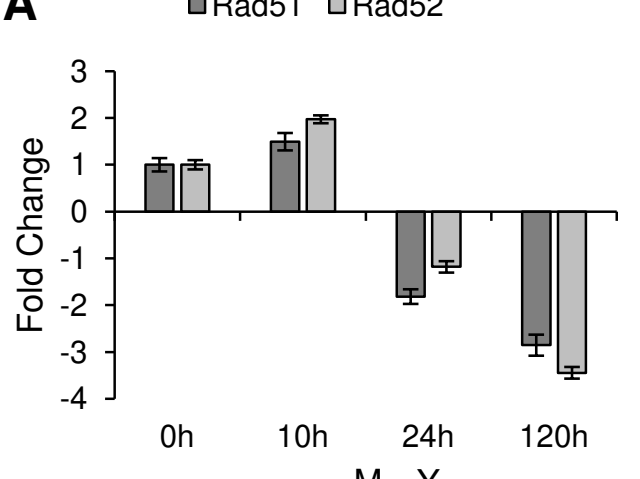

B $\quad$ aRad51 $\square$ Rad52

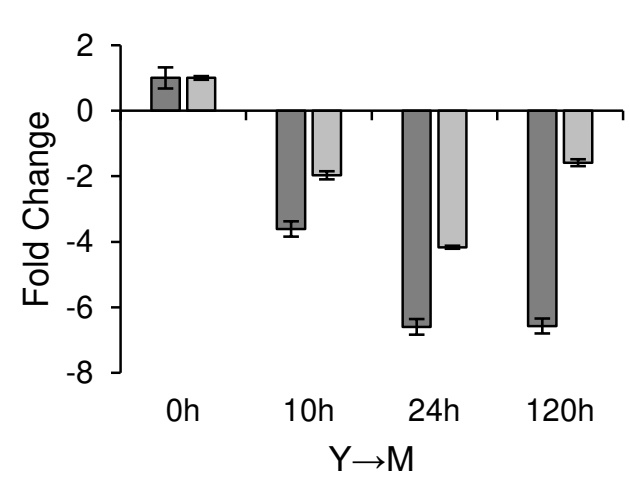

Figure 3. Expression profile of homologous recombination related genes during morphological switch. (A) Expression of Rad51 and Rad52 during mycelium to yeast transition. The switch to pathogenic form of $P$. brasiliensis occurs with decreasing of HR related genes after 24h. (B) When the fungus was switched to hours.

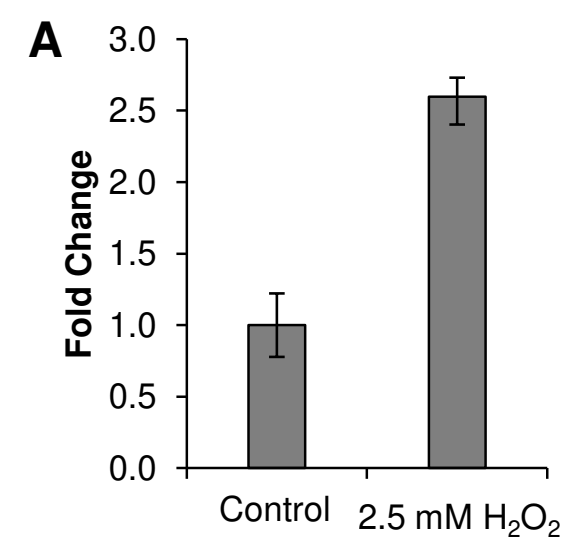

B

Figure 4. KU70 expression during oxidative stress or heat shock. (A) Transcript levels of Ku70 increased after $2.5 \mathrm{mM}$ peroxide treatment. (B) A modest increase was

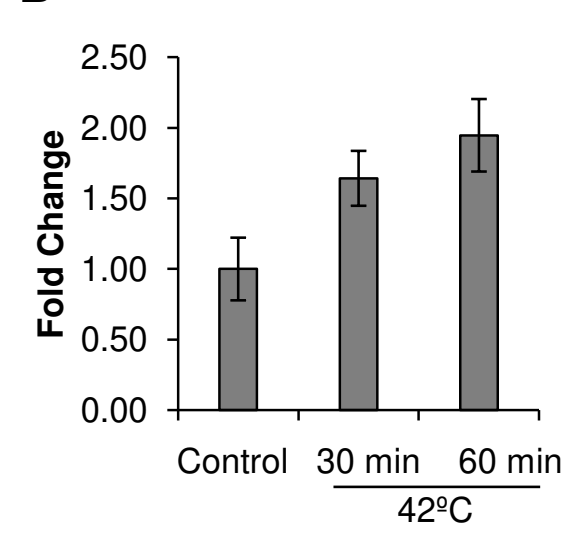
we added $\mathrm{H}_{2} \mathrm{O}_{2}$

A
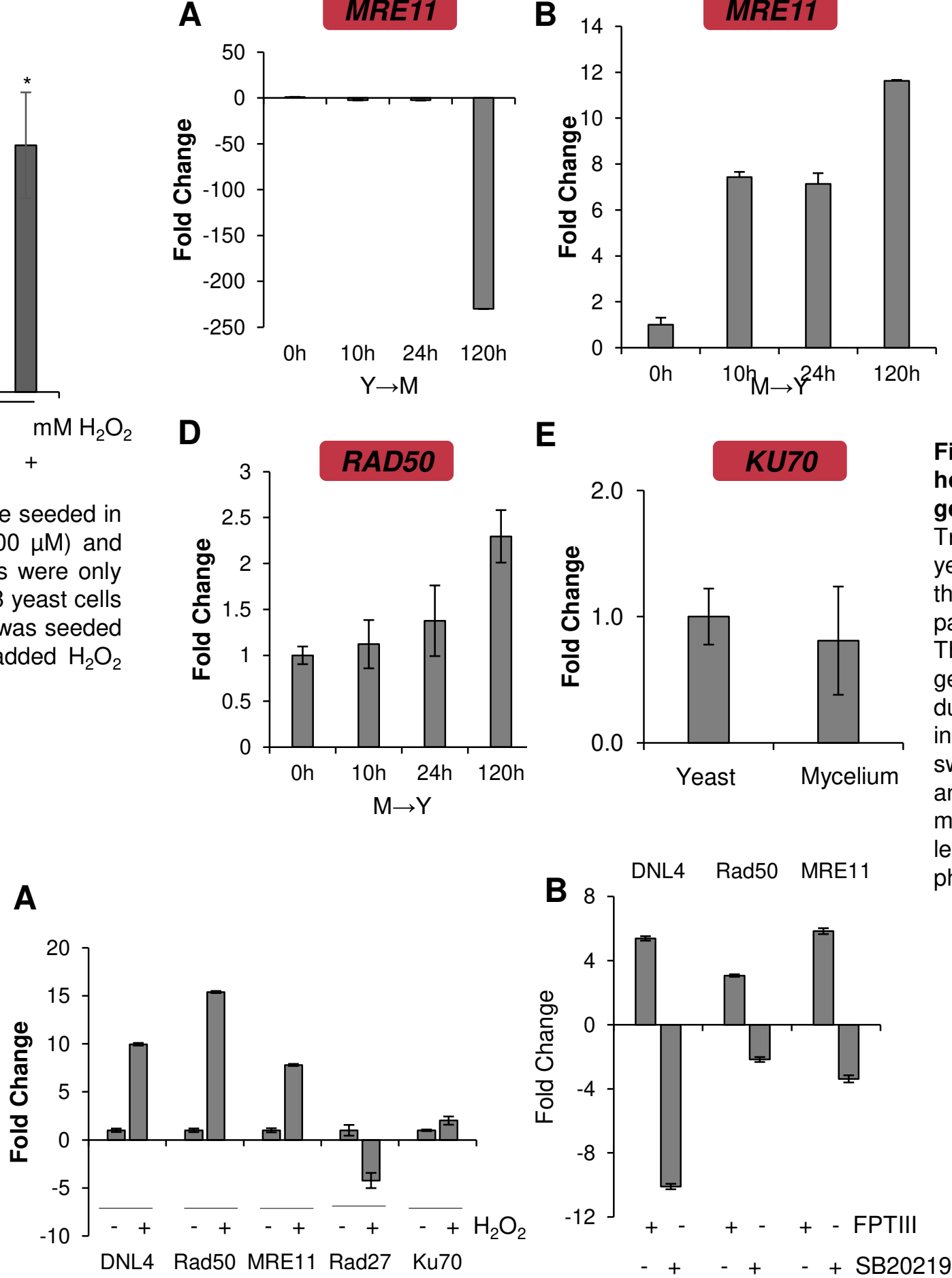

Figure 5. A crosstalk between Ras and Hog pathways may control the NHEJ repair machinery. (A) Transcript levels of NHEJ genes increased after treatment with high concentration of hydrogen peroxide. (B) NHEJ genes are regulated by Ras MAPK as seen by the increasing in transcript levels after Ras inhibitor (50 $\mu \mathrm{M}$ FPT II) treatment. After HOG1 inhibilon ( $10 \mu \mathrm{M}$ SB202190), NHEJ genes reduced transcript levels revealing that Hog1 may be important for response to oxidative stress via activation of DNA repair machinery. Data from experiments at presence of inhibitors are displayed as fold change related to references not treated with peroxide.

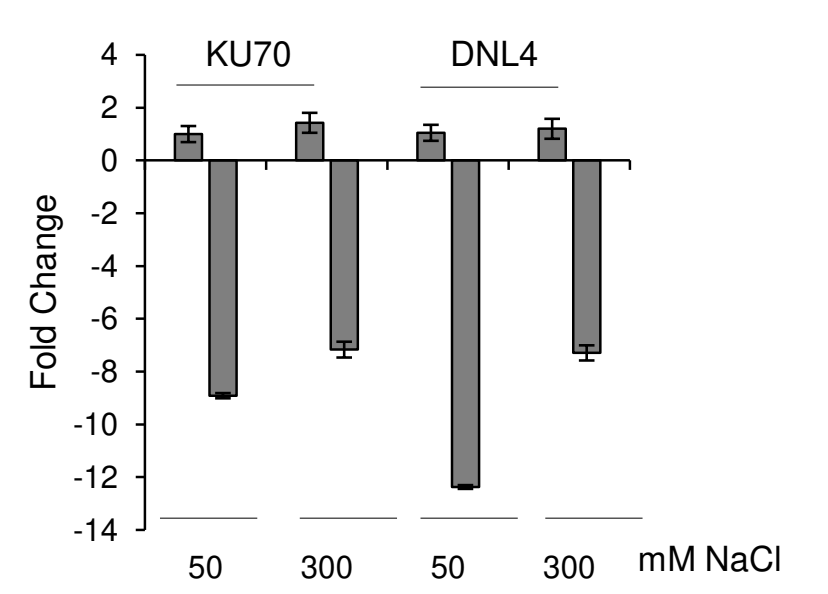

+ SB202190

Figure 6. NHEJ related genes have their expression controlled by Hog1 pathway. KU70 and DNL4 genes have transcript levels decreased after Hog1 inhibition (10 $\mu \mathrm{M}$ SB202190) when submitted to osmotic stress. Genes related to NHEJ modestly increase transcript levels after osmotic stress, but have an importan reduction after Hog1 inhibition when yeast cells were treated with 50 or $300 \mathrm{mM}$ of $\mathrm{NaCl}$.

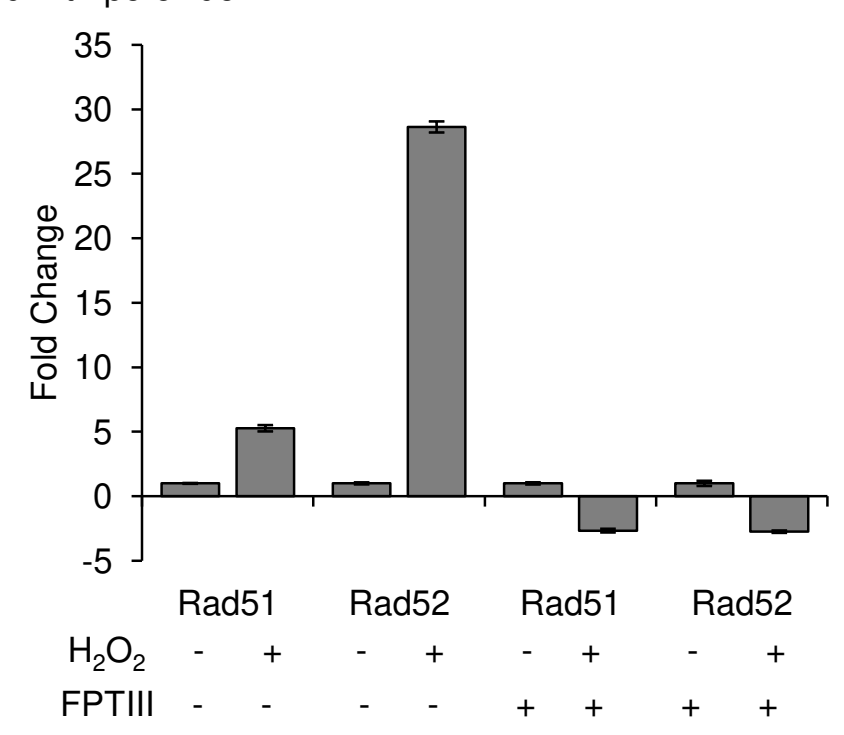

Figure 7. HR related genes are under control of Ras MAPK pathway. P. brasiliensis yeast cells were treated with $50 \mu \mathrm{M}$ of Ras Prote treated with $50 \mu \mathrm{M}$ of Ras Tad51 and Rad52 transcripts ar increased in remoxs to oxidative respond to oxidative stress, probably because of decreased HR genes iress. After Ras inhibition, yeast cels reduced their capabilitive

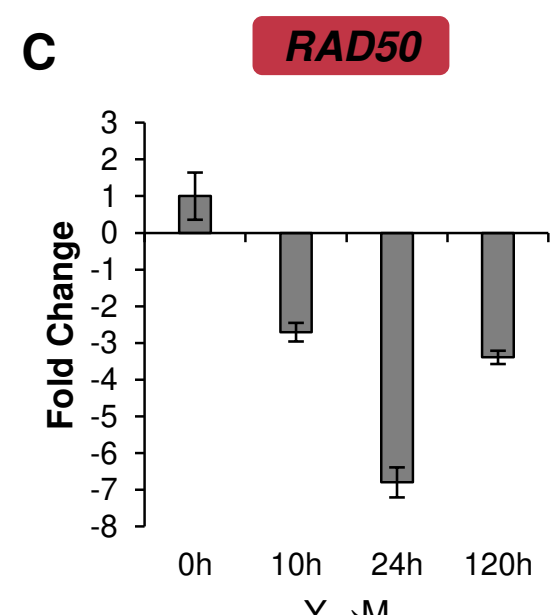

Figure 2. Expression profile of nonomologous end joining pathway related ranscripts for MRE11 are decrosed during reast to mycelium transition $(Y \rightarrow M)$, while $(B)$ he same gene was increased during The game profile was observed for RAD50 ene, which decreased transcript levels environmental switch $(Y \rightarrow M)$, while (D) switch. and RAD50 were altered during mels were not altered despite the specific expression. 